\title{
Initial Investigation of the Small Feature Detection Capability of the ORNL Fast Neutron Tomographic Imaging System
}

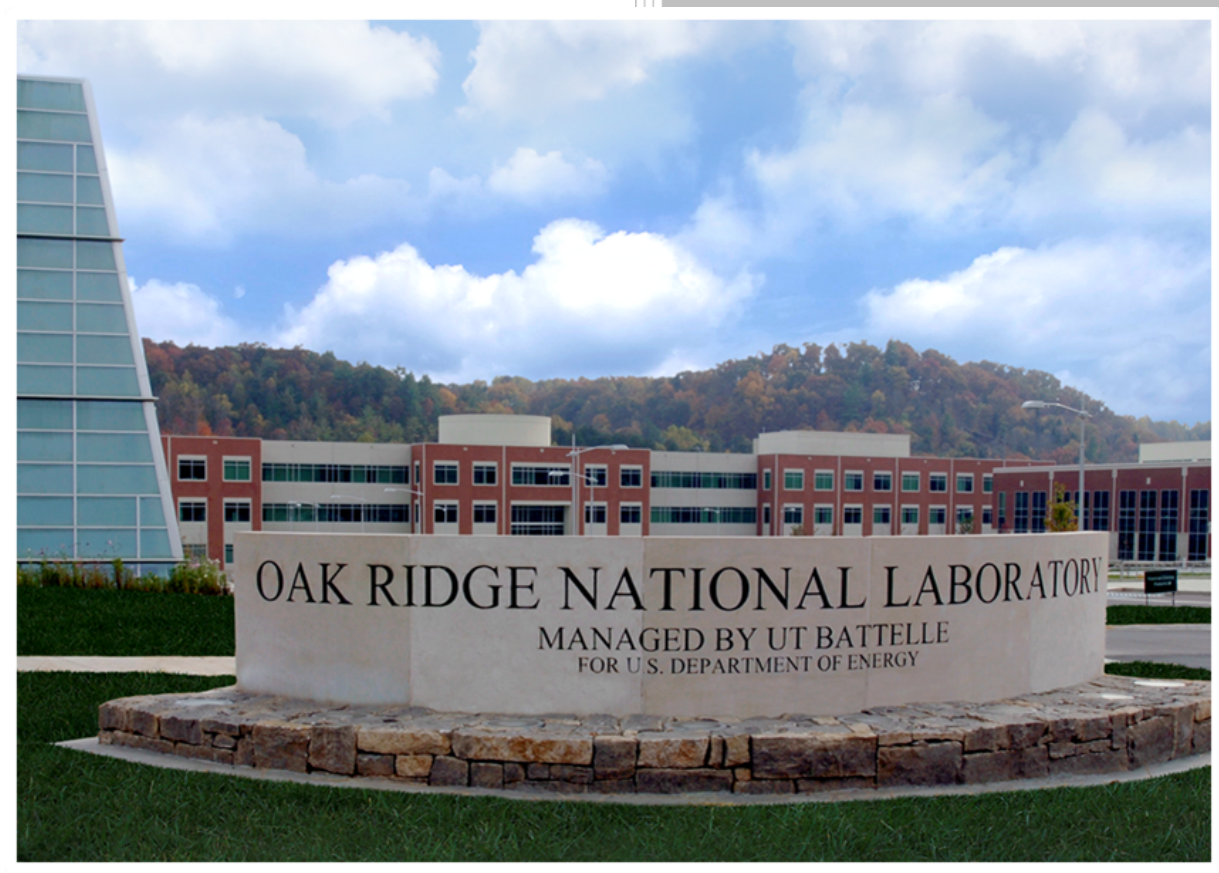

\section{Approved for public release.}

Distribution is unlimited.

Michael Wright

Eric Nelius John Mihalczo Seth McConchie

Paul Hausladen

April 2018 


\title{
DOCUMENT AVAILABILITY
}

Reports produced after January 1, 1996, are generally available free via US Department of Energy (DOE) SciTech Connect.

Website www.osti.gov

Reports produced before January 1, 1996, may be purchased by members of the public from the following source:

\author{
National Technical Information Service \\ 5285 Port Royal Road \\ Springfield, VA 22161 \\ Telephone 703-605-6000 (1-800-553-6847) \\ TDD 703-487-4639 \\ Fax 703-605-6900 \\ E-mail info@ntis.gov \\ Website http://classic.ntis.gov/
}

Reports are available to DOE employees, DOE contractors, Energy Technology Data Exchange representatives, and International Nuclear Information System representatives from the following source:

Office of Scientific and Technical Information

PO Box 62

Oak Ridge, TN 37831

Telephone 865-576-8401

Fax 865-576-5728

E-mail reports@osti.gov

Website http://www.osti.gov/contact.html

This report was prepared as an account of work sponsored by an agency of the United States Government. Neither the United States Government nor any agency thereof, nor any of their employees, makes any warranty, express or implied, or assumes any legal liability or responsibility for the accuracy, completeness, or usefulness of any information, apparatus, product, or process disclosed, or represents that its use would not infringe privately owned rights. Reference herein to any specific commercial product, process, or service by trade name, trademark, manufacturer, or otherwise, does not necessarily constitute or imply its endorsement, recommendation, or favoring by the United States Government or any agency thereof. The views and opinions of authors expressed herein do not necessarily state or reflect those of the United States Government or any agency thereof. 
Nuclear Security and Isotope Technology Division

INITIAL INVESTIGATION OF THE SMALL FEATURE DETECTION CAPABILITY OF THE ORNL FAST NEUTRON TOMOGRAPHIC IMAGING SYSTEM

\author{
Michael Wright \\ Eric Nelius \\ John Mihalczo \\ Seth McConchie \\ Paul Hausladen
}

Date Prepared: April 2018

Prepared by

OAK RIDGE NATIONAL LABORATORY

Oak Ridge, TN 37831-6283

managed by

UT-BATTELLE, LLC

for the

US DEPARTMENT OF ENERGY

under contract DE-AC05-00OR22725 


\section{CONTENTS}

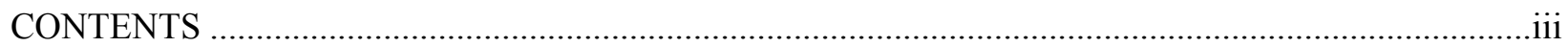

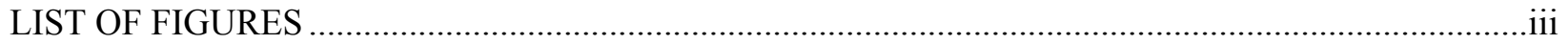

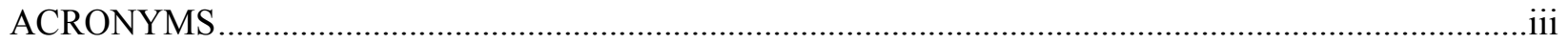

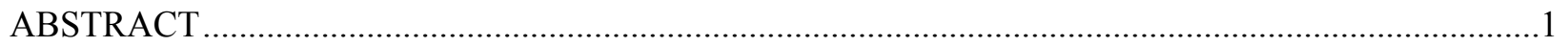

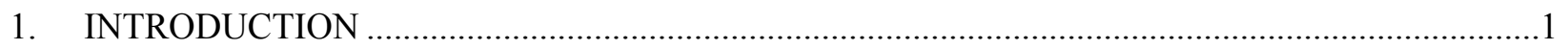

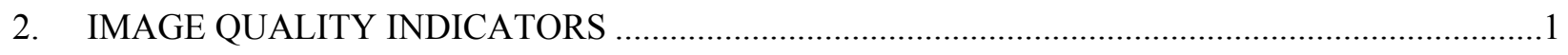

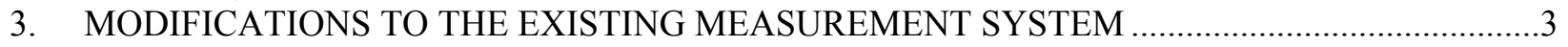

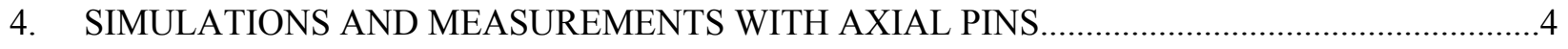

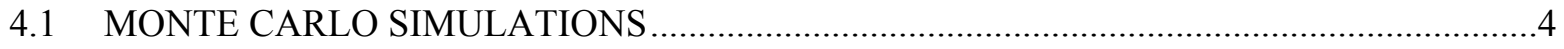

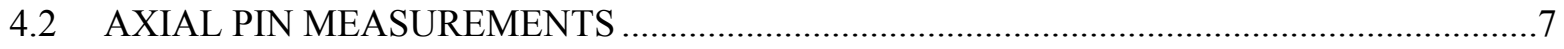

5. SIMULATIONS AND MEASUREMENTS WITH SURFACE INSERTS …................................11

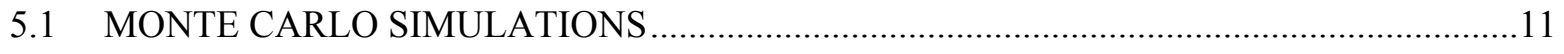

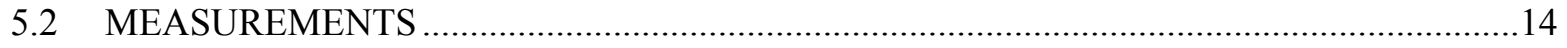

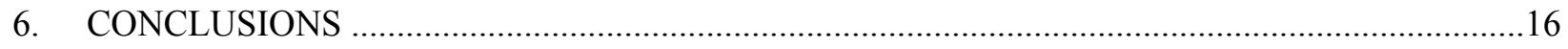

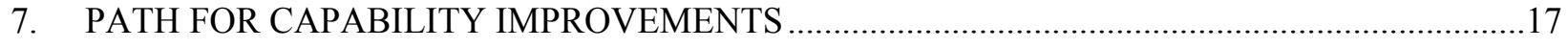

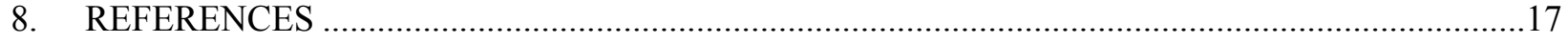




\section{LIST OF FIGURES}

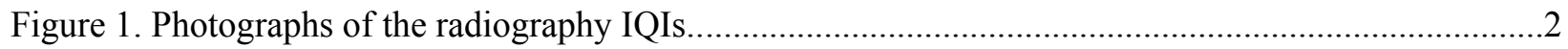

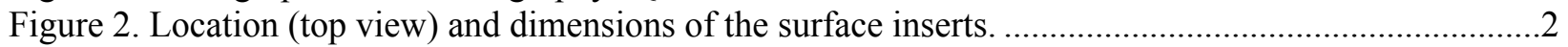

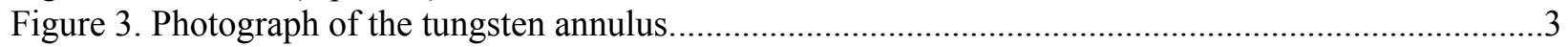

Figure 4. Photograph of the modified neutron detector arm..............................................................

Figure 5. Photograph of the ING-27 DT generator mounted in the imaging system. ................................

Figure 6. Cross section of the Monte Carlo model used for the simulations. ...............................................5

Figure 7. Monte Carlo simulated tomographic image of the axial pin IQI................................................6

Figure 8. Monte Carlo simulated tomographic image of the axial pin IQI subjected to a $3.5 \mathrm{~mm}$

Gaussian blur filter.

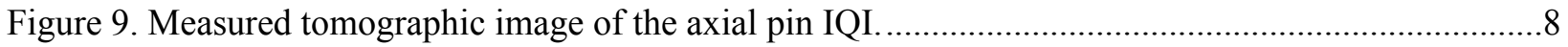

Figure 10. Raw and processed sinograms of the axial pin measurement. ............................................

Figure 11. Measured axial pin tomographic image after noise reduction.................................................10

Figure 12. Attenuation profile of a $3 \mathrm{~mm}$ slice through the horizontal diameter of the tomograph............11

Figure 13. Attenuation profile of a $3 \mathrm{~mm}$ slice near the perimeter of the tomograph. .............................11

Figure 14. Monte Carlo simulated tomographic image of the surface insert IQI. .................................12

Figure 15. Neutron attenuation coefficient as a function of angle at a radius just inside the surface..........13

Figure 16. Monte Carlo simulated tomographic image of the axial pin IQI subjected to a $3.5 \mathrm{~mm}$

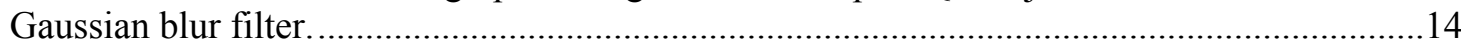

Figure 17. Measured tomographic image of the surface insert IQI. .....................................................15

Figure 18. Locations of the attenuation length computation paths.......................................................16

Figure 19. Measured neutron attenuation coefficient as a function of angle at a radius just inside the surface (upper) and deeper in the interior (lower)............................................................. 16 


\section{ACRONYMS}

API associated particle imaging

DD deuterium deuterium

DT deuterium tritium

HDPE high-density polyethylene

IQI image quality indicators

MLEM Maximum Likelihood Expectation Maximization

MCNP-PoliMi Monte Carlo Neutron Particle-Politecnico di Milano

OD outer diameter

ORNL Oak Ridge National Laboratory 


\begin{abstract}
A variety of fast neutron imaging simulations and measurements were performed to investigate the spatial resolution and small feature detection capability of a version of the Oak Ridge National Laboratory fast neutron tomographic imaging system. Two image quality indicators were examined: (1) a variety of long steel pins embedded axially in the interior of a polyethylene cylinder, and (2) a variety of short steels pins embedded radially in the surface of a polyethylene cylinder. Measurements demonstrated detectability of about $3 \mathrm{~mm}$. Further data analysis may show improved detection performance and allow a more precise determination of the spatial resolution. Our current simulation code takes only partial consideration of the DT generator neutron production spot size, with neutron production effectively originating at a single point. Simulations showed that features less than $2 \mathrm{~mm}$ should be detectable with an improved generator. Our current ING-27 DT generator has a neutron production spot size of about $3.5 \mathrm{~mm}$, which appears to be the limiting factor at present. Generators with spot sizes as small as $1 \mathrm{~mm}$ are commercially available. Higher-power, small-spot size associated particle generators are at the prototype stage and are expected to be commercially available soon.
\end{abstract}

\title{
1. INTRODUCTION
}

Neutron radiography and tomography have been used for a number of applications in science, industry, and national security. They provide information that is complementary to X-ray radiography and tomography because neutrons and X-rays interact with matter differently. Most neutron radiography has been performed with thermal neutrons because it is practical to build a thermal neutron detector with high efficiency and high spatial resolution. The high penetration power of fast neutrons makes it correspondingly difficult to make a high-efficiency and high-spatial resolution fast neutron detector. On the source side, the production of a collimated thermal neutron beam of useful cross-sectional area and intensity requires a nuclear reactor or large accelerator. Fast neutrons can be produced by compact DD (deuterium-deuterium) and DT (deuterium-tritium) neutron generators, californium decay, or alpha-n sources. These produce fewer neutrons but have the advantage of being effectively point sources for radiography. A DT generator produces neutrons by accelerating deuterium ions into a tritium loaded target. The deuterium and tritium fuse, emitting a neutron isotropically (in the center of mass) and an alpha particle in the opposite direction. A significant advantage of DT neutron generators is that they can be constructed with internal alpha detectors to allow each generated neutron to be time and direction tagged via detection of its associated alpha particle. This is referred to as associated particle imaging (API). Oak Ridge National Laboratory has been performing API for many years and has constructed multiple varieties of API radiography systems. One of these, called the Nuclear Materials Identification System [1], uses an API DT neutron generator and multiple $25 \mathrm{~mm} \times 25 \mathrm{~mm} \times 100 \mathrm{~mm}$ plastic scintillators as neutron detectors. This report documents the initial investigation of the ability to perform neutron tomography with a spatial resolution on a scale of a few-millimeters using $25 \mathrm{~mm}$ neutron detectors and API neutron generators in a transportable system. Simulations and measurements of two image quality indicators were performed to investigate the performance possibilities of this technique.

\section{IMAGE QUALITY INDICATORS}

Photographs of the radiography image quality indicators (IQI) are shown in Figure 1. They consist of two high-density polyethylene (HDPE) cylinders of 3.25 or 3.45-inch outer diameter (OD) and 3-inch height: the smaller diameter cylinder has two sets of axial steel pins, and the larger diameter one has a set of steel surface inserts. The axial pins have diameters of 5, 3, 2, 2, 1, and $1 / 2 \mathrm{~mm}$ and are distributed along a diameter and along an arc near the surface. The surface inserts range from $1 \mathrm{~mm}$ diameter and depth to $5 \mathrm{~mm}$ diameter and depth. The dimensions and location of the surface inserts are given in Figure 2. The 
surface insert IQI fits snugly inside a 3.46-inch-ID and 5.0-inch-OD tungsten annulus. A photograph of the tungsten annulus is provided in Figure 3.

The axial pin IQI serves to determine basic spatial resolution for an item of only moderate contrast and substantial scattering, whereas the heavily shielded surface insert IQI serves to determine performance for a geometry that is very challenging for X-rays.

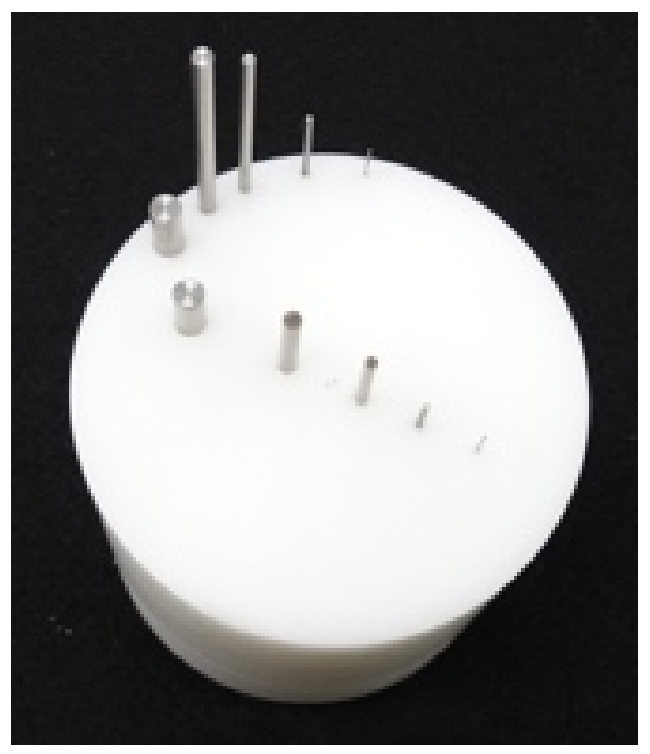

Axial Pins

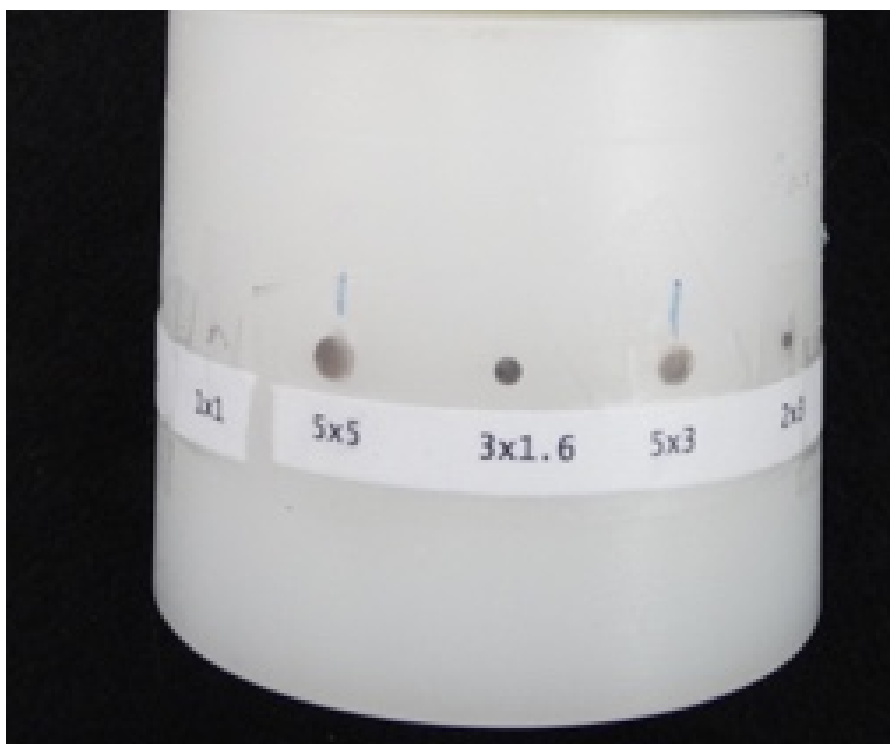

Surface Inserts

Figure 1. Photographs of the radiography IQIs..

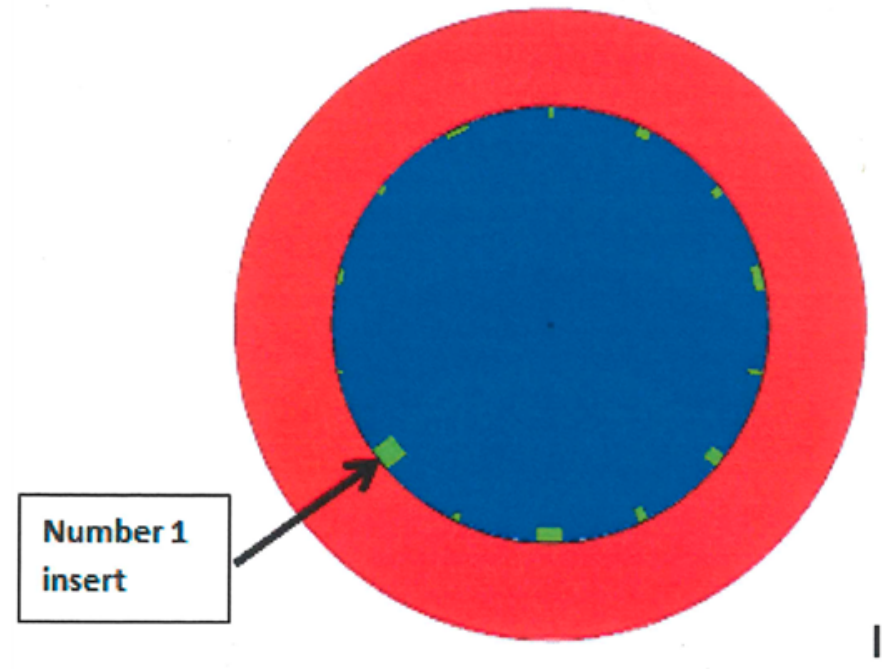

\begin{tabular}{|ccc|}
\hline Number & $\begin{array}{l}\text { Diameter } \\
(\mathrm{mm})\end{array}$ & $\begin{array}{l}\text { Depth } \\
(\mathrm{mm})\end{array}$ \\
\hline \hline $1^{*}$ & 5.0 & 5.0 \\
2 & 1.6 & 1.6 \\
\hline 3 & 5.0 & 3.0 \\
4 & 2.0 & 3.0 \\
5 & 3.0 & 3.0 \\
6 & 1.0 & 3.0 \\
\hline 7 & 5.0 & 2.0 \\
8 & 2.0 & 2.0 \\
9 & 3.0 & 2.0 \\
10 & 1.0 & 2.0 \\
\hline 11 & 5.0 & 1.0 \\
12 & 2.0 & 1.0 \\
13 & 3.0 & 1.0 \\
14 & 1.0 & 1.0 \\
\hline
\end{tabular}

* Listed counterclockwise from insert number 1

Figure 2. Location (top view) and dimensions of the surface inserts. 


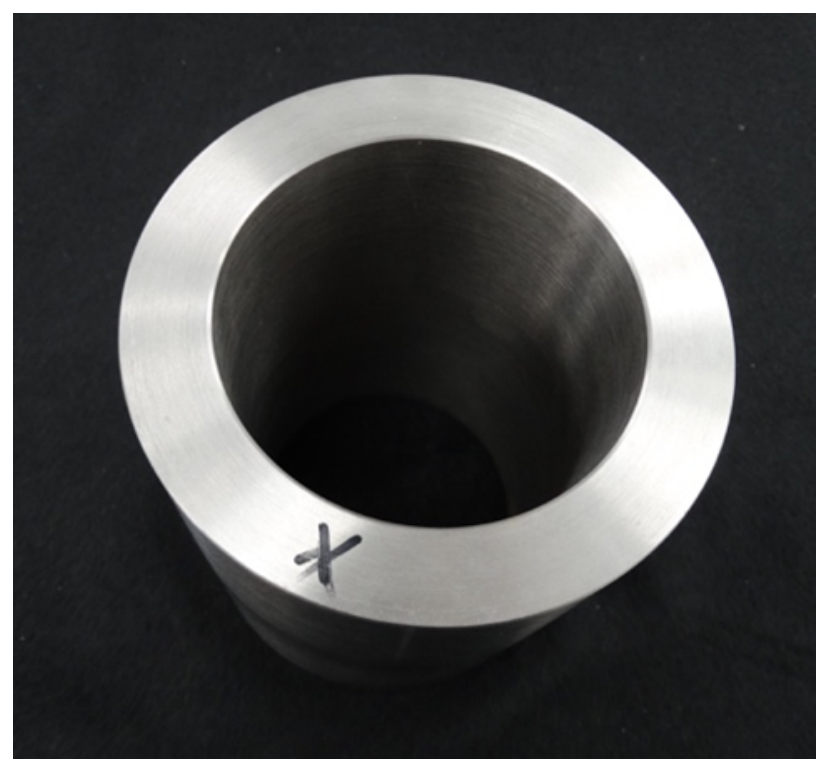

Figure 3. Photograph of the tungsten annulus.

\section{MODIFICATIONS TO THE EXISTING MEASUREMENT SYSTEM}

An existing laboratory version of a Nuclear Materials Identification System was modified to improve small feature performance for these measurements. The system uses 32 neutron detectors that are $25 \times 25100 \mathrm{~mm}$ plastic scintillators coupled to a $25 \mathrm{~mm}$ photomultiplier tube. They are mounted to one of several arms of different radii, depending on the needs of the measurement. An arm with a radius of $217 \mathrm{~cm}$ was available from an earlier measurement campaign on air cargo containers. This arm was extended to span a 60 degree arc and to hold 62 detectors. The large arm radius allowed us to achieve a magnification of up to about $20 \times$ by placing the small IQI close to the DT generator's fan-beam output. This ability to use magnification is an important advantage of using a fan beam for illumination because a magnification factor of 20 makes a $25 \mathrm{~mm}$ detector effectively $1.25 \mathrm{~mm}$ at the location of an object being imaged. The drawback is that the count rate decreases by $1 / r$ as the radius of the line of detectors is increased. The $217 \mathrm{~cm}$ radius was selected because it was already available, rather than as a result of an optimization calculation. A photograph of the expanded arm is shown in Figure 4. The apparent missing detectors in the array are actually present but wrapped in black tape to block light leaks. What appears to be a second row of detectors above the actual detectors are small HDPE spacer blocks used in attachment of the detectors to the imaging apparatus. Figure 5 shows a photograph of the ING-27 generator mounted in the imaging system. 


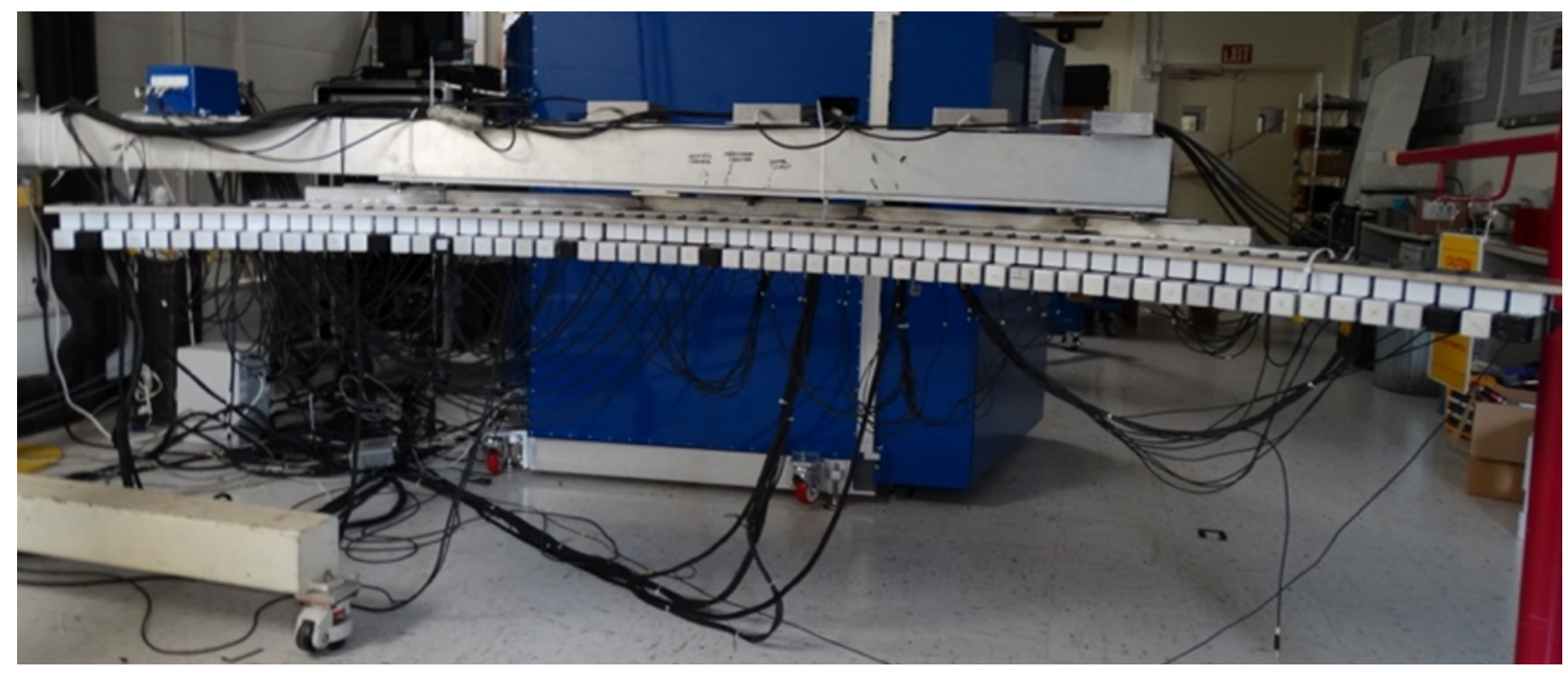

Figure 4. Photograph of the modified neutron detector arm.

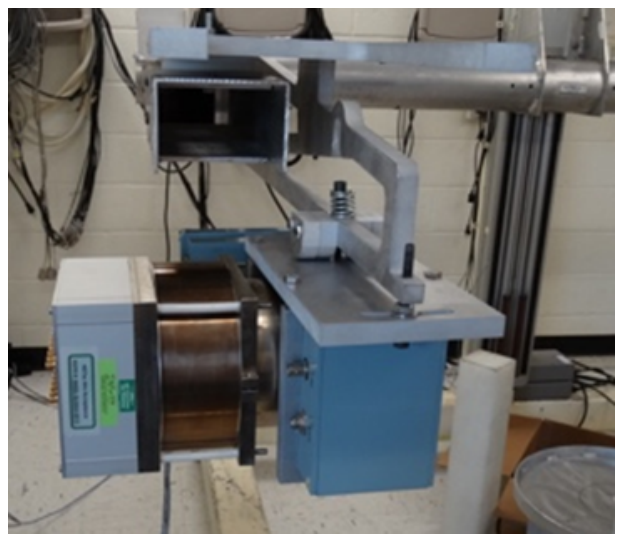

Figure 5. Photograph of the ING-27 DT generator mounted in the imaging system.

\section{SIMULATIONS AND MEASUREMENTS WITH AXIAL PINS}

\subsection{MONTE CARLO SIMULATIONS}

A horizontal cross section of the geometry for the simulations of the measurements of the axial pin IQI of Figure 1 is given in Figure 6. This simulation contained additional pins not present in the physical IQI with diameters of 1.25 and $1.3 \mathrm{~mm}$ in the lower section of the cross-sectional model. The other pin diameters were $5,3,2,1$, and $1 / 2 \mathrm{~mm}$. These pins were spaced along the HDPE diameter and near the outer surface.

The maximum likelihood expectation maximization (MLEM)-reconstructed image from the Monte Carlo simulations of an equivalent of 10 hours of measurement time is given in Figure 7. The 5, 3, and $2 \mathrm{~mm}$ pins are clearly visible. The 1.3,1.2, and $1 \mathrm{~mm}$ pins are visible in the image if it is known where they are located, but they are not clearly distinguishable from residual noise and artifacts in the reconstructed 
image. We did not have an opportunity to investigate the use of statistical methods to distinguish small features from background noise. The $1 / 2-\mathrm{mm}$-OD pins were not detectable and are barely visible, even in the model (Figure 6).

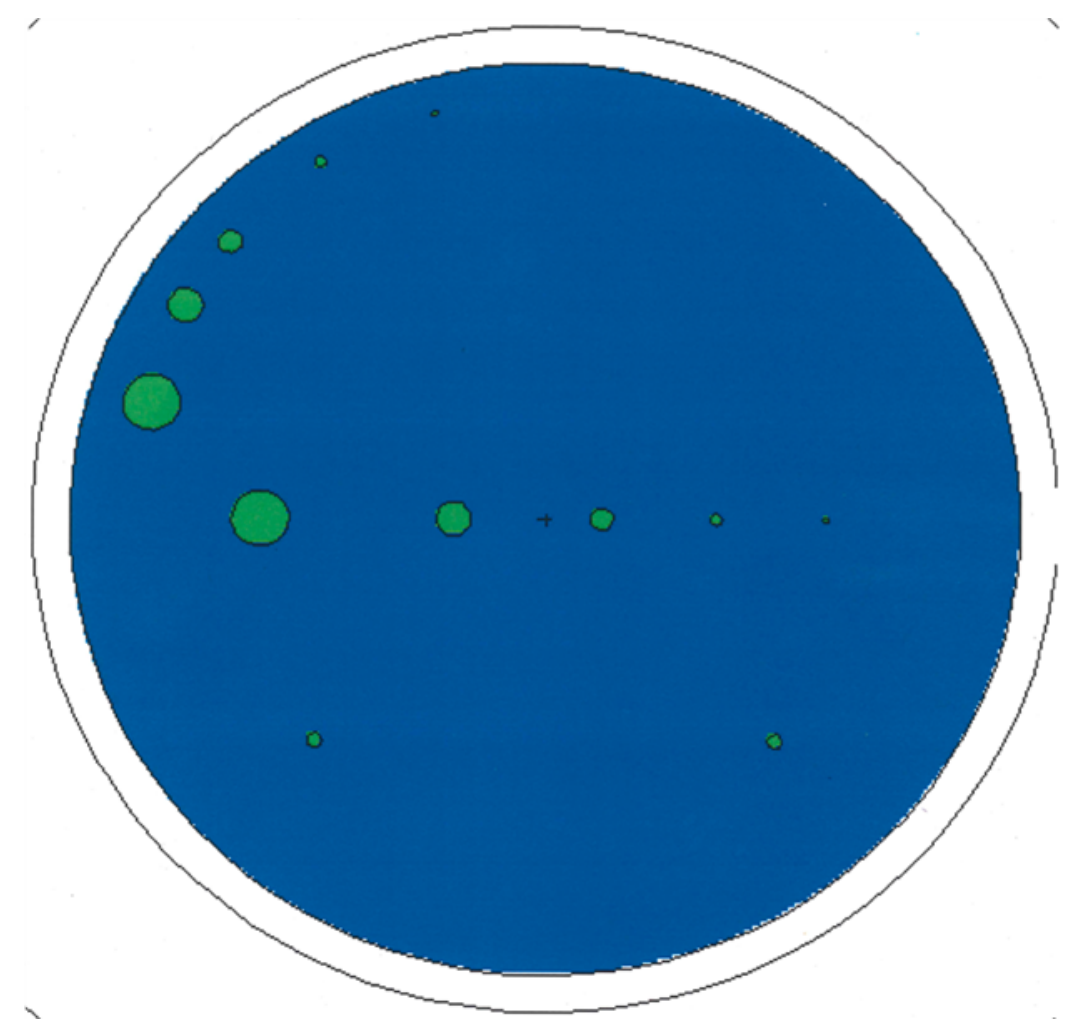

Figure 6. Cross section of the Monte Carlo model used for the simulations. 


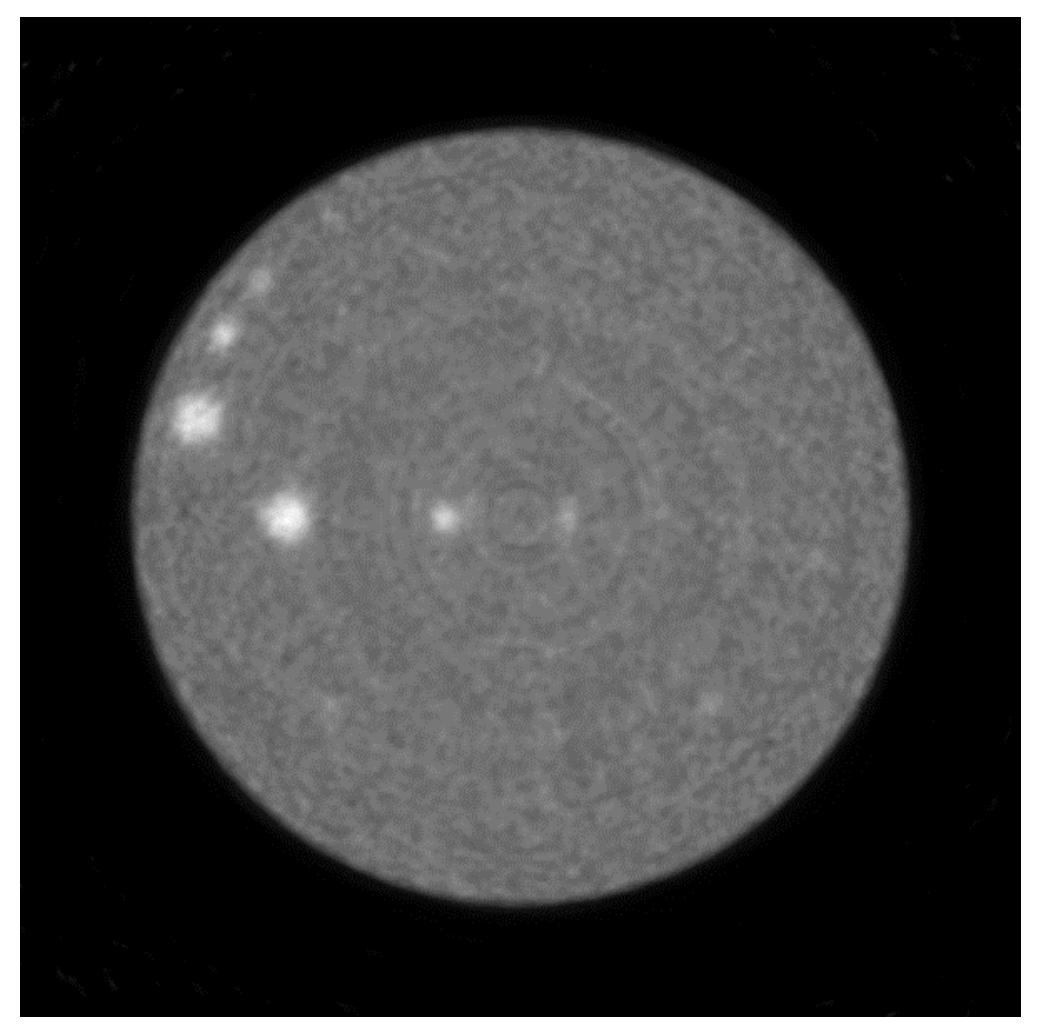

Figure 7. Monte Carlo simulated tomographic image of the axial pin IQI.

Our simulations using MCNP-PoliMi have worked well for many years for the types of measurements we have traditionally performed. However, the results of these new small-feature measurements (discussed below) were significantly different from the simulations. We investigated and found that although the Monte Carlo measurement simulation code accounts for the DT generator spot size (i.e., the diameter of the deuterium beam where it impacts the tritium target) in determining the neutron cone angle (and thus the coincidence detection efficiency necessary to determine absolute neutron attenuation lengths), it does not account for the effect of the DT generator spot size on spatial resolution. The code effectively assumes that the neutrons all originate at a point in the center of the target. The actual spot size is about $3.5 \mathrm{~mm}$. These simulations should be interpreted as indicative of the capabilities of a system with the same detectors and electronics, but an improved DT neutron generator (spot sizes of $1 \mathrm{~mm}$ are commercially available). Modification of our simulation code was beyond the time and budget available for this project, so as a first approximation of the appearance of the tomographic image taking account of the DT spot size, the simulated image was subjected to a Gaussian blur filter of $3.5 \mathrm{~mm}$ in an image editing program, shown in Figure 8. This filter also blurs the MLEM reconstruction artifacts, so the image noise is not correct. In this image, the $5 \mathrm{~mm}$ and $3 \mathrm{~mm}$ spots remain clearly visible, but visibility of the $2 \mathrm{~mm}$ spots is marginal. 


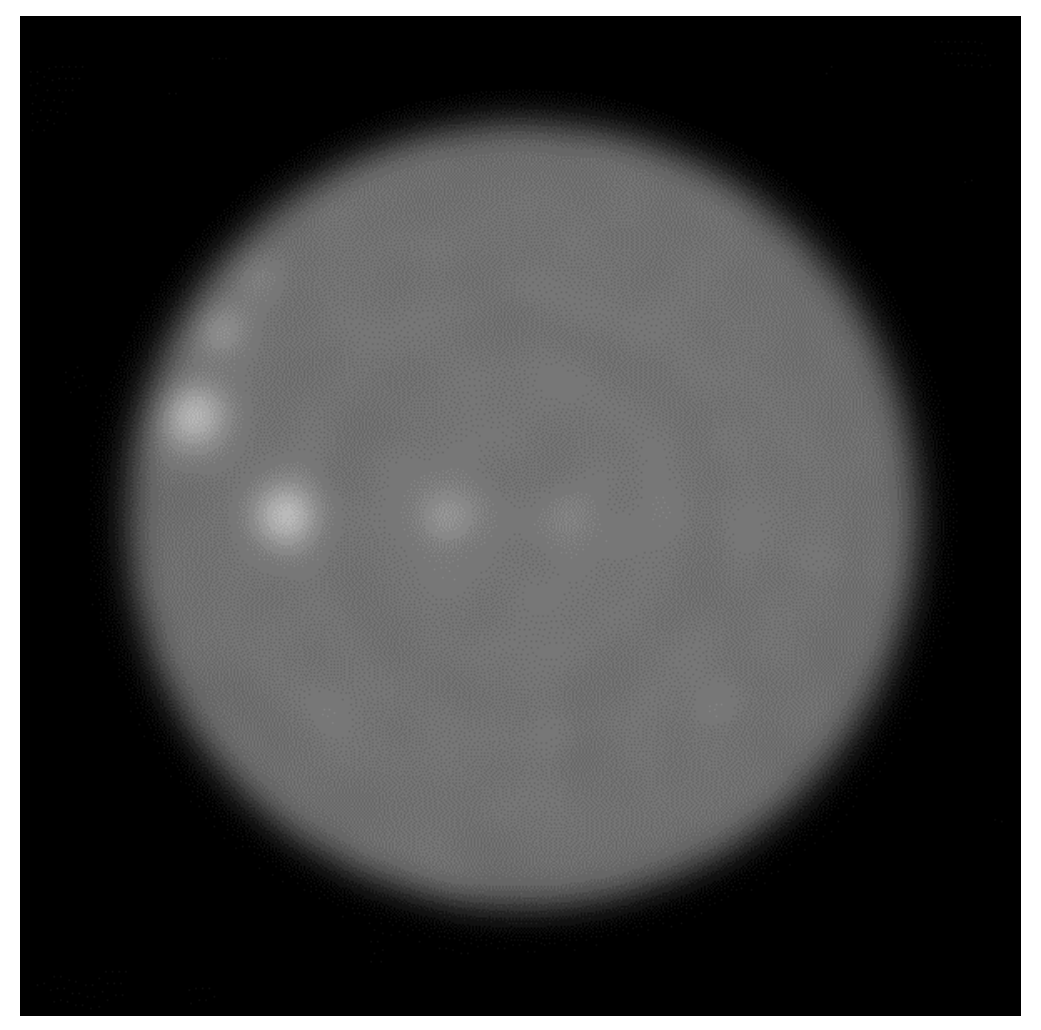

Figure 8. Monte Carlo simulated tomographic image of the axial pin IQI subjected to a $3.5 \mathrm{~mm}$ Gaussian blur filter.

\subsection{AXIAL PIN MEASUREMENTS}

Measurements of the axial pin IQI were made with an array of 62 detectors that were stepped in 4 angular increments of $1 / 4$ of the angular spacing between the detector centers resulting in a total of 248 effective detector positions. The sample was rotated in 6-degree steps for a total of 60 positions with a total live time of about 24 hours. Data was acquired on 6 different days. Void (calibration) measurements were also made each day by raising the source and detectors to a position above the sample. The individual measurements were combined by adding all the sample neutron counts, separately adding all the void neutron counts, and then taking the logarithmic ratio of the sums. The reconstructed tomographic image from the measurements is shown in Figure 9. The $5 \mathrm{~mm}$ pins are easily visible, and the $3 \mathrm{~mm}$ pins are apparent. There is a weak indication of the $2 \mathrm{~mm}$ pins if it is known where to look, and there is no indication of the smaller pins. Although the blurring of reconstruction noise complicates comparison, the general appearance of this image is consistent with the Gaussian blurred version of the simulated image. 


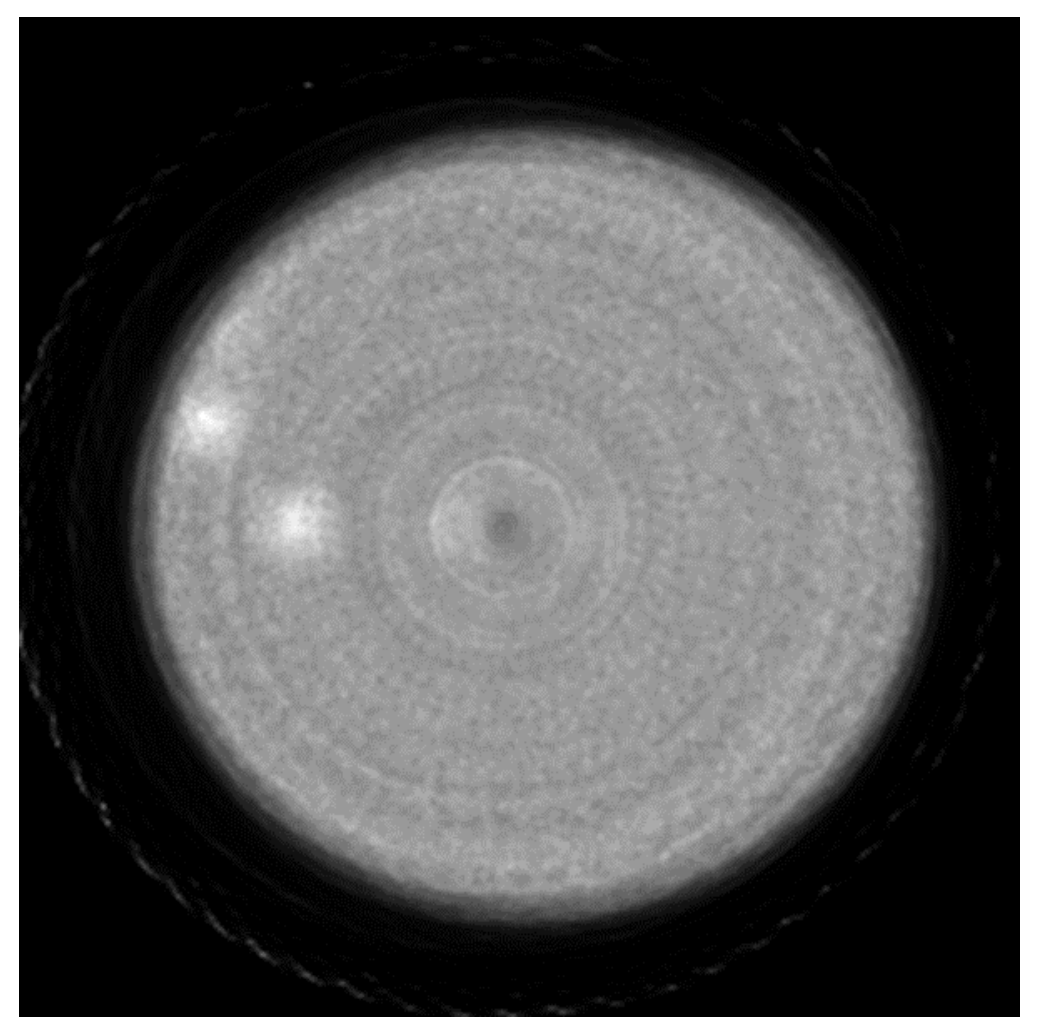

Figure 9. Measured tomographic image of the axial pin IQI.

The rings in the reconstructed tomographic image indicate correlated nonrandom noise in the attenuation profiles at each of the 60 rotations. These rings increase the signal-to-noise ratio in the image and reduce detectability of the pins. The raw sinogram of the measurement is shown on the upper half of Figure 10. Each row of the sinogram represents the attenuation profile for one of the 60 projections. Each column represents the output of an individual neutron detector. Thus, the vertical streaks in the image are instrumental artifacts due to improper gain normalization among the 62 neutron detectors. To reduce this nonrandom noise, the overall sinogram was collapsed to a single plot of attenuation length versus neutron detector angle by summing all 60 sample position projections. This measured curve was fit to a smooth spline curve, and the difference of these two curves yielded a gain correction factor for each detector. This correction factor was then applied to each detector in each project ion, yielding the sinogram on the lower half of Figure 10. 

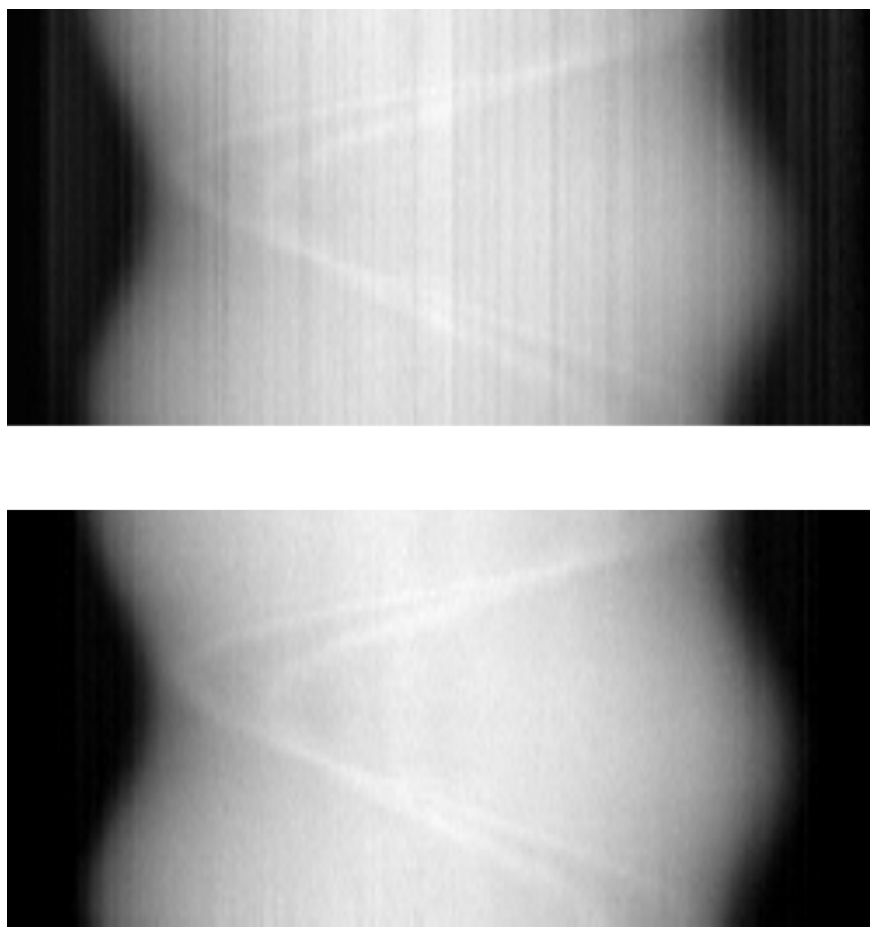

Figure 10. Raw and processed sinograms of the axial pin measurement.

The processed sinogram was reconstructed to yield the tomographic image in Figure 11. The ring-shaped artifacts are greatly reduced, but the overall visibility of the pins is not substantially changed. Since all data were stored in list mode, it may be possible to further improve the result by reprocessing the data, adjusting coincidence windows, signal delays, void normalizations, etc. 


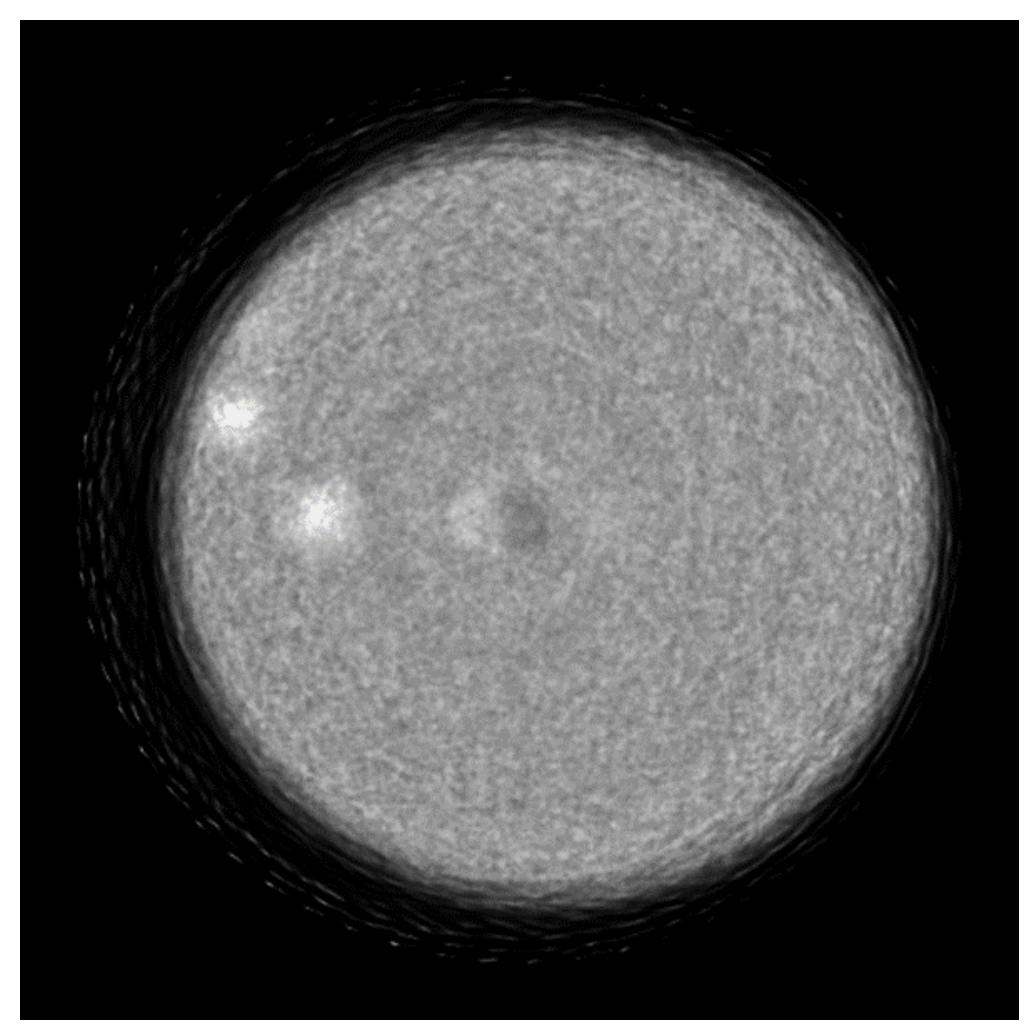

Figure 11. Measured axial pin tomographic image after noise reduction.

As an alternative presentation of the measurement, a $3 \mathrm{~mm}$ slice through the reconstructed image in Figure 11 was computed and is shown in Figure 12, which displays the neutron attenuation coefficient as a function of lateral position. The $5 \mathrm{~mm}$ pin is clearly visible, the $3 \mathrm{~mm}$ pin is weakly visible, and there is an indication of the $2 \mathrm{~mm}$ pin. An anomalous feature in the central region of the image is a frequent characteristic of MLEM reconstructions of noisy tomographic data, and in this particular case, one appears as a dip. The full width at half maximum of the $5 \mathrm{~mm}$ pin image is about $6 \mathrm{~mm}$ or $7 \mathrm{~mm}$, depending on the assumed peak shape. This value is consistent with a value of $6.1 \mathrm{~mm}$, which would result from the convolution of a $5 \mathrm{~mm}$ pin size with the $3.5 \mathrm{~mm}$ DT generator spot size. This convolution process would yield a $4.6 \mathrm{~mm}$ image for the $3 \mathrm{~mm}$ pin and a $4.0 \mathrm{~mm}$ image for the $2 \mathrm{~mm}$ pin. These values are consistent with the image, but the high signal-to-noise ratio makes this result inconclusive. A $3 \mathrm{~mm}$ wide annular slice, with its outer edge located $3 \mathrm{~mm}$ inside the HDPE, was computed to look for the impact of the pins located near the perimeter of the cylinder and is shown in Figure 13. The $5 \mathrm{~mm}$ and $3 \mathrm{~mm}$ pins are visible, but there is no indication of the $2 \mathrm{~mm}$ pin. These pins were spaced with their edges $1 \mathrm{~mm}$ inside the HDPE, rather than having their centers at a constant distance from the edge. As a result, the smaller pins have their material at a closer average distance to the edge and more of their signal is averaged with the edge because of the DT generator spot size. The impact of the DT generator spot size is also apparent in the two attenuation coefficient plots. The measured attenuation coefficient of the baseline is about 0.11 in the interior of the cylinder, whereas it is only about 0.07 near the edge due to the inclusion of some of the region outside the HDPE when determining the attenuation near the edge. 


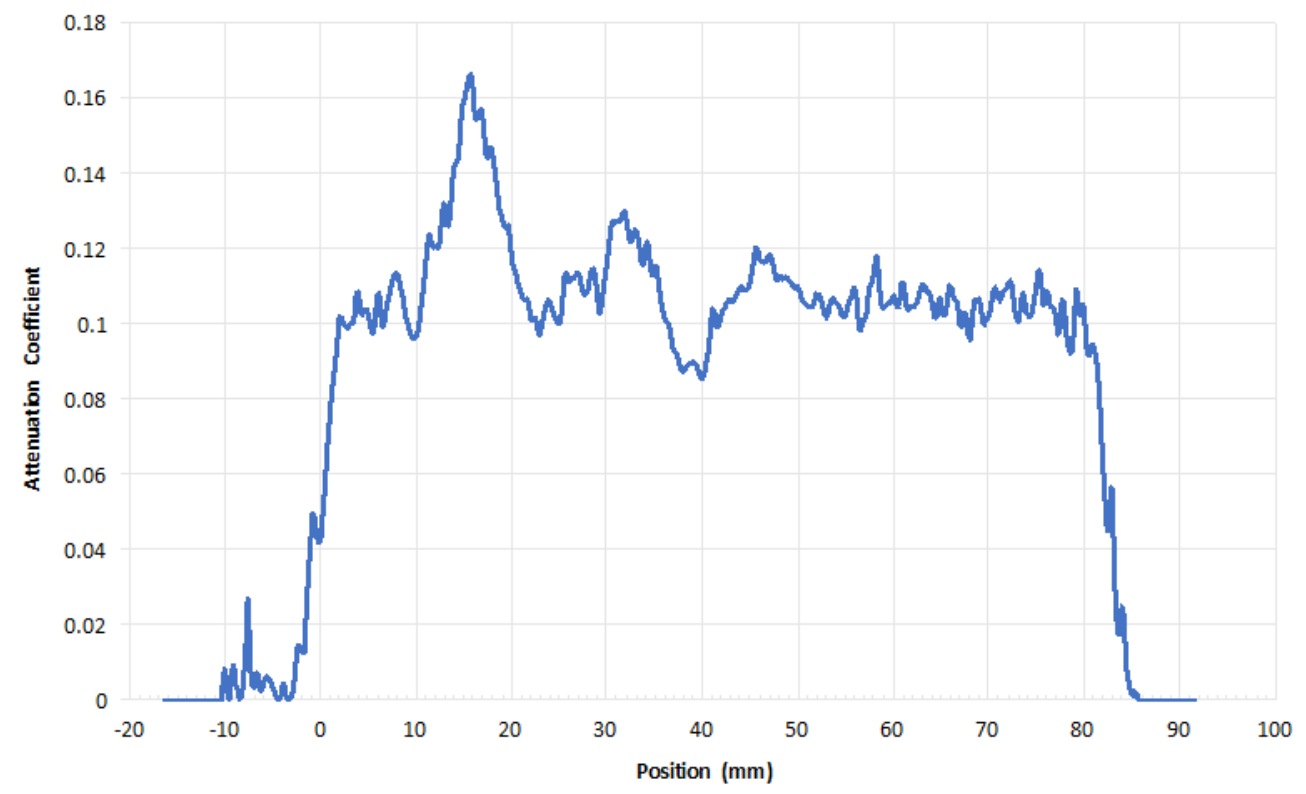

Figure 12. Attenuation profile of a $3 \mathrm{~mm}$ slice through the horizontal diameter of the tomograph.

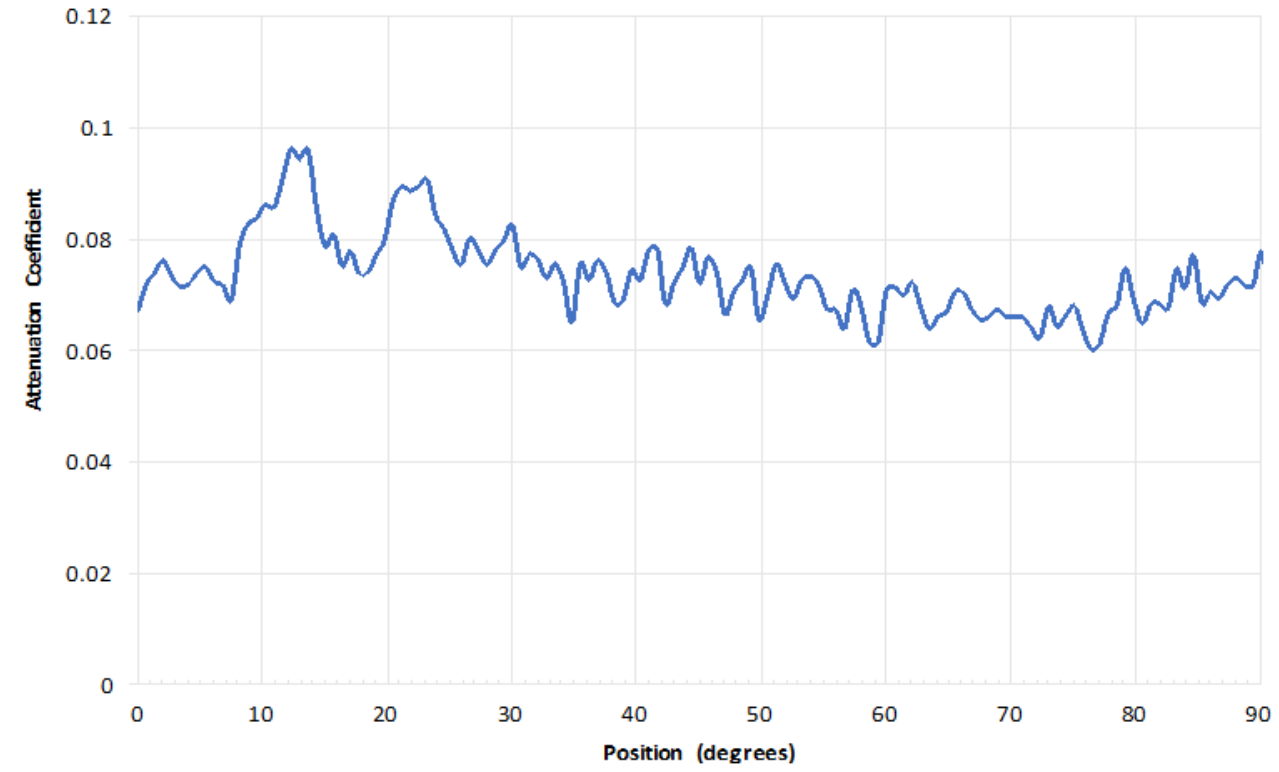

Figure 13. Attenuation profile of a $3 \mathrm{~mm}$ slice near the perimeter of the tomograph.

\section{SIMULATIONS AND MEASUREMENTS WITH SURFACE INSERTS}

\subsection{MONTE CARLO SIMULATIONS}

A horizontal cross section of the geometry for the simulations of the measurements of the surface insert radiography IQI shown in Figure 2. Simulations were performed for a bare HDPE configuration and for the HDPE located inside the tungsten annulus. The MLEM reconstructed image of the shielded IQI from 
an equivalent of 15 hours of measurement time is given in Figure 14. About half of the inserts are visible. Some of the inserts with either dimension less than $2 \mathrm{~mm}$ may be visible, but only if their location is known beforehand.

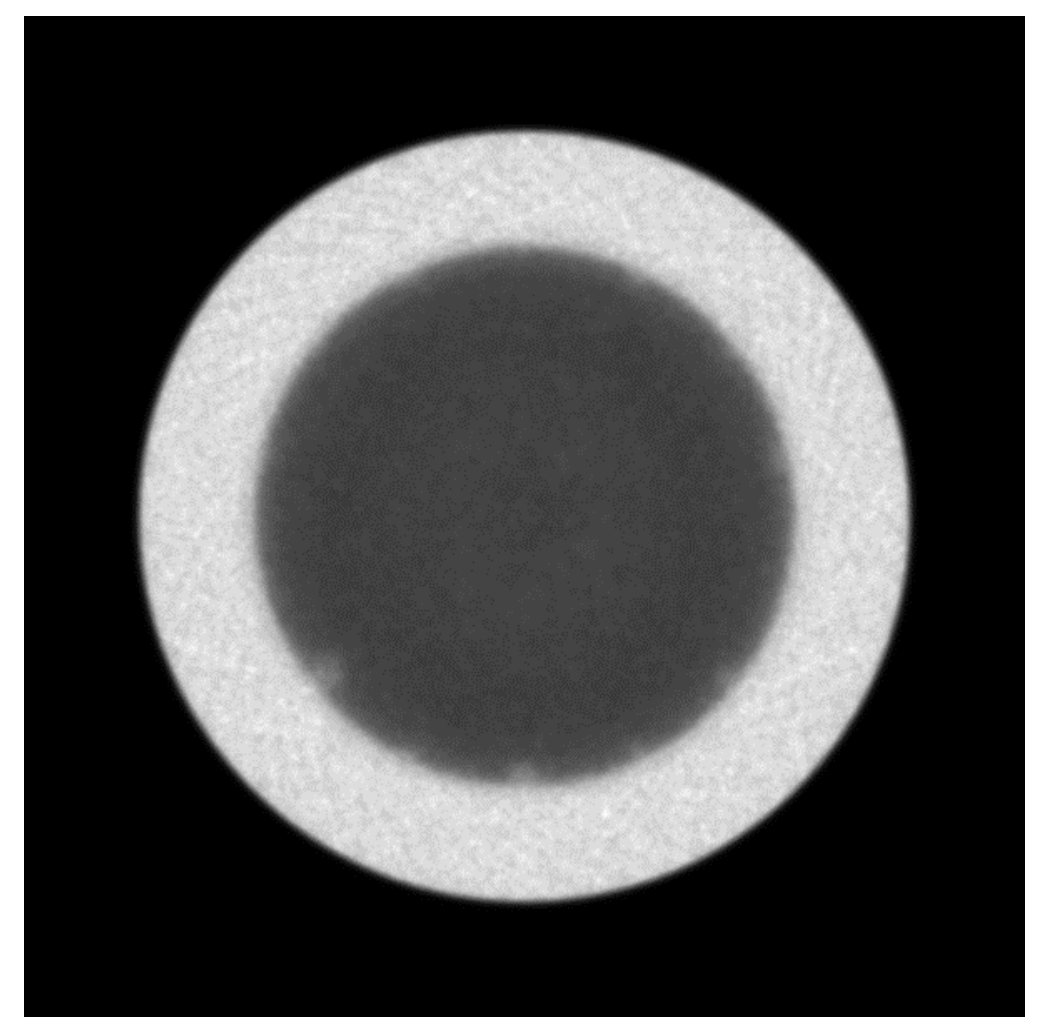

Figure 14. Monte Carlo simulated tomographic image of the surface insert IQI.

Figure 15 shows a plot of the neutron attenuation length around the perimeter of the cylinder at a radius that is just inside the surface of the HDPE. The peaks are labeled according to the table in Figure 2. 


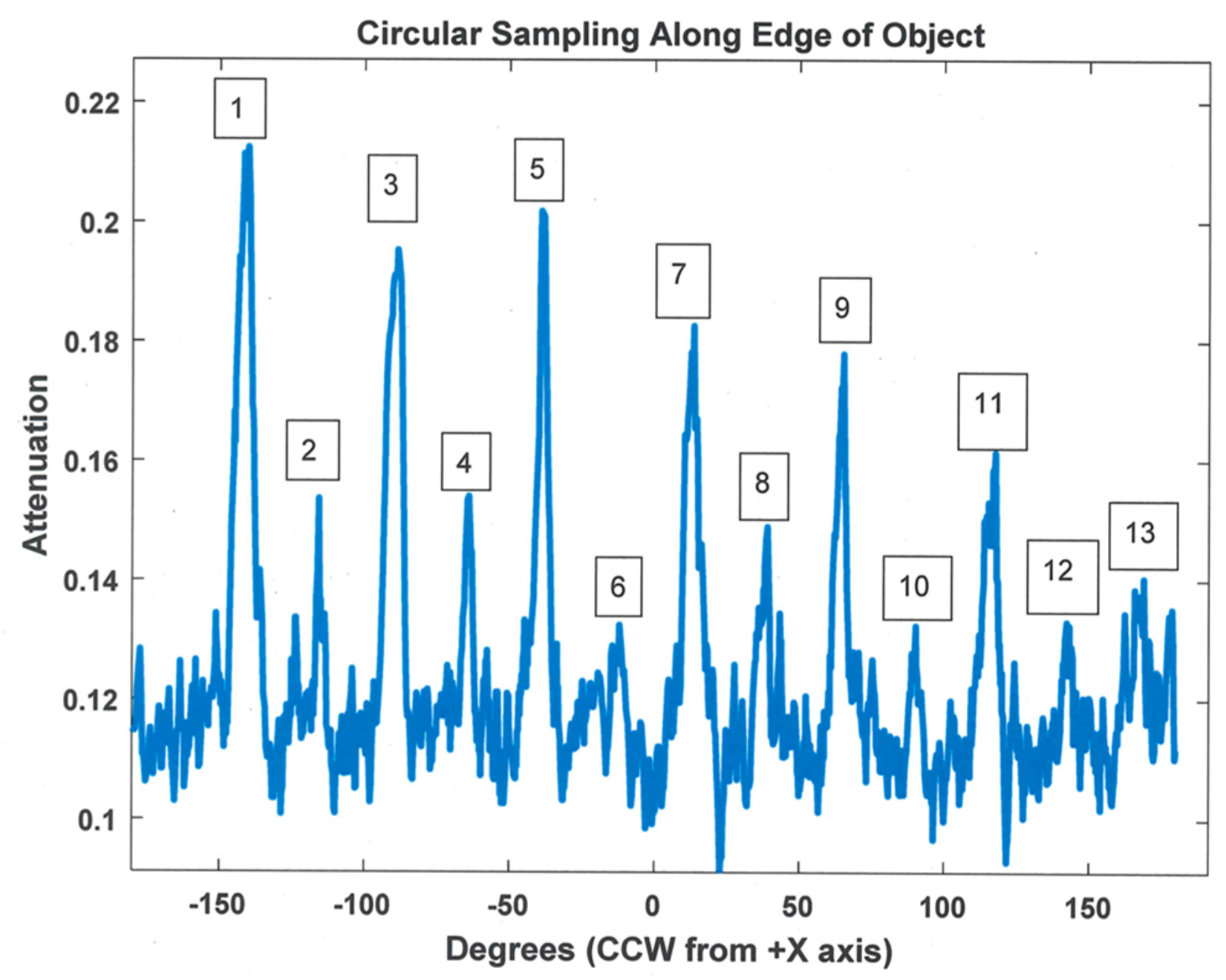

Figure 15. Neutron attenuation coefficient as a function of angle at a radius just inside the surface.

This attenuation length plot shows at least some indication of the presence of all of the surface inserts except the one which was 1-mm-OD, 1-mm-deep. Visibility of the smaller pins is assisted because their angular locations are known. Recall, these simulations are indicative of the potential performance of a system with a small spot size generator and a large fan beam magnification factor.

As was done for the simulated axial pin image, the simulated surface insert image was subjected to a $3.5 \mathrm{~mm}$ Gaussian blur filter in an image editing program. The results are shown in Figure 16. A few of larger inserts remain visible, but most can no longer be seen. 


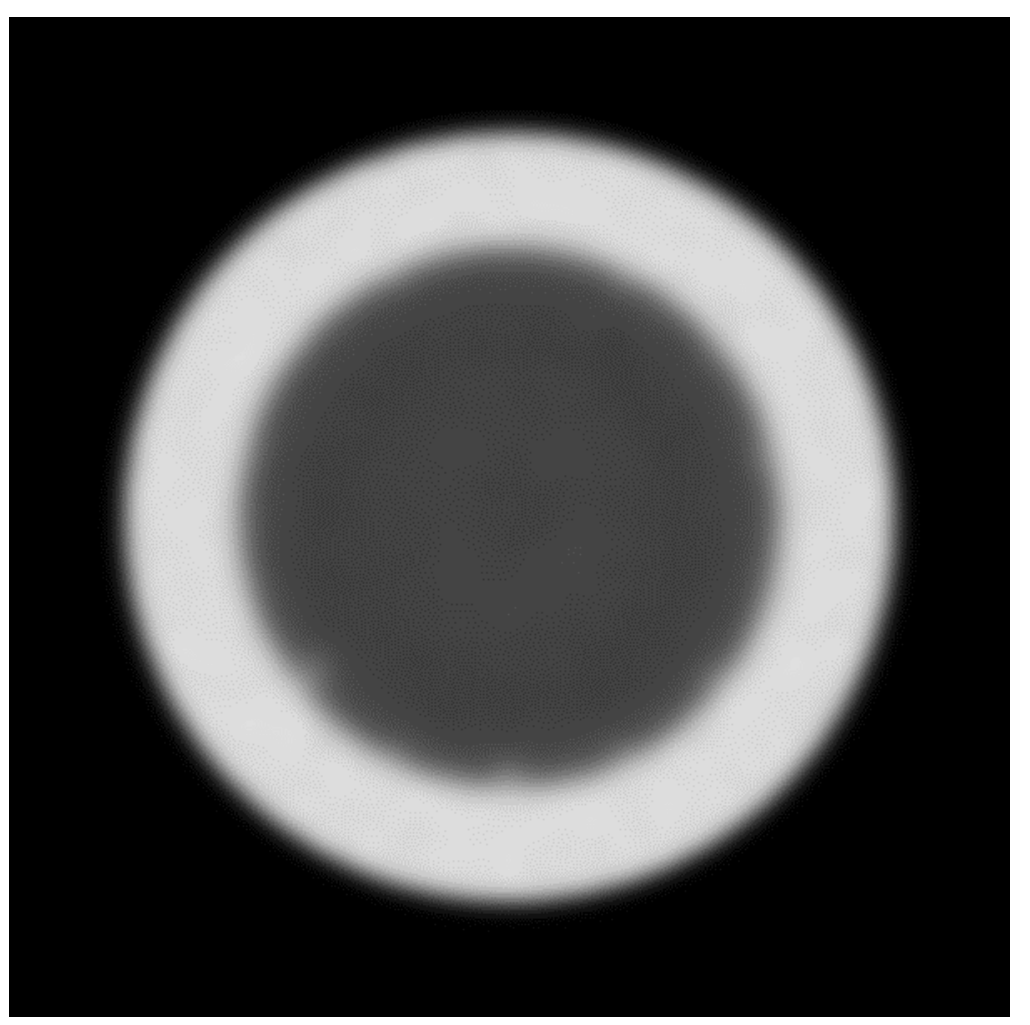

Figure 16. Monte Carlo simulated tomographic image of the axial pin IQI subjected to a $3.5 \mathrm{~mm}$ Gaussian blur filter.

\subsection{MEASUREMENTS}

The experimental setup for the surface insert measurements was the same as for the axial pin measurements except that the object was farther from the source to allow room for the surrounding tungsten annulus. Total measurement time was 28 hours. The measured surface insert sinogram was processed with the same de-noising operation as the axial pin sinogram, and the reconstructed tomographic image is shown in Figure 17. The general appearance of the image is consistent with the blurred simulated image in Figure 16. The two largest inserts are visible, and there are suggestions of a few more. 


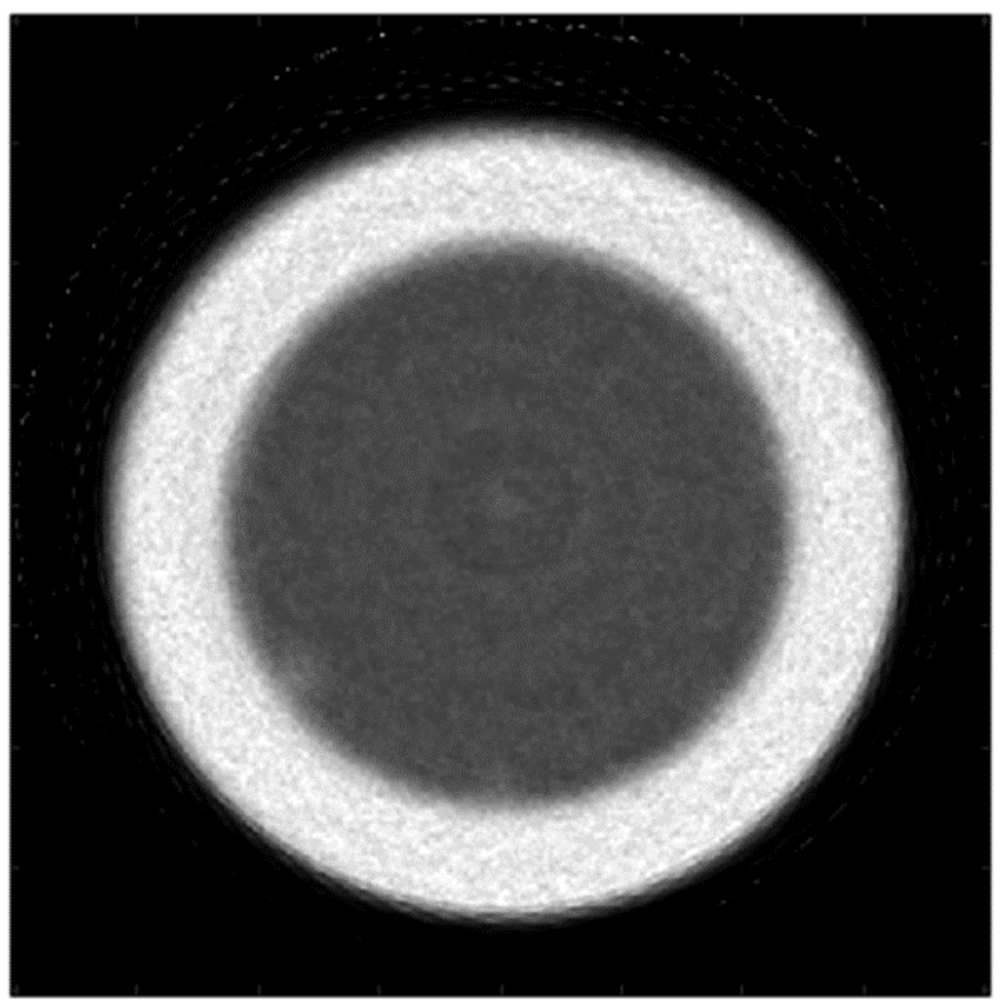

Figure 17. Measured tomographic image of the surface insert IQI.

As was done for the simulated data, neutron attenuation length was computed around the perimeter at a radius that is just inside the surface of the HDPE as plotted on the left side of Figure 18. For comparison with the baseline noise, the attenuation length was also computed at a smaller radius well away from the inserts, as plotted on the right side of Figure 18. The resulting attenuation lengths are shown in Figure 19. As was the case with the axial pin IQI, the measured baseline attenuation coefficient is different in the interior of the HDPE than near the edge. For this IQI, the attenuation is higher near the edge, presumably because the signal being mixed in from the exterior region is from the highly attenuating tungsten rather than from the air that surrounded axial pin IQI. Peaks corresponding to inserts with a diameter times depth of about 6 or more are visible in the upper plot. Our decision to locate all inserts in the same plane turned out to be unfortunate. The measured peaks have a full width at half maximum (FWHM) of about 10 degrees and span about 15 degrees at the base. The inserts were spaced around the HDPE at intervals of about 25 degrees, and the small and large inserts were interleaved. This means that the plots in Figure 19 show multiple almost adjacent peaks, and it is difficult to visually separate actual peaks from apparent baseline statistical noise. 

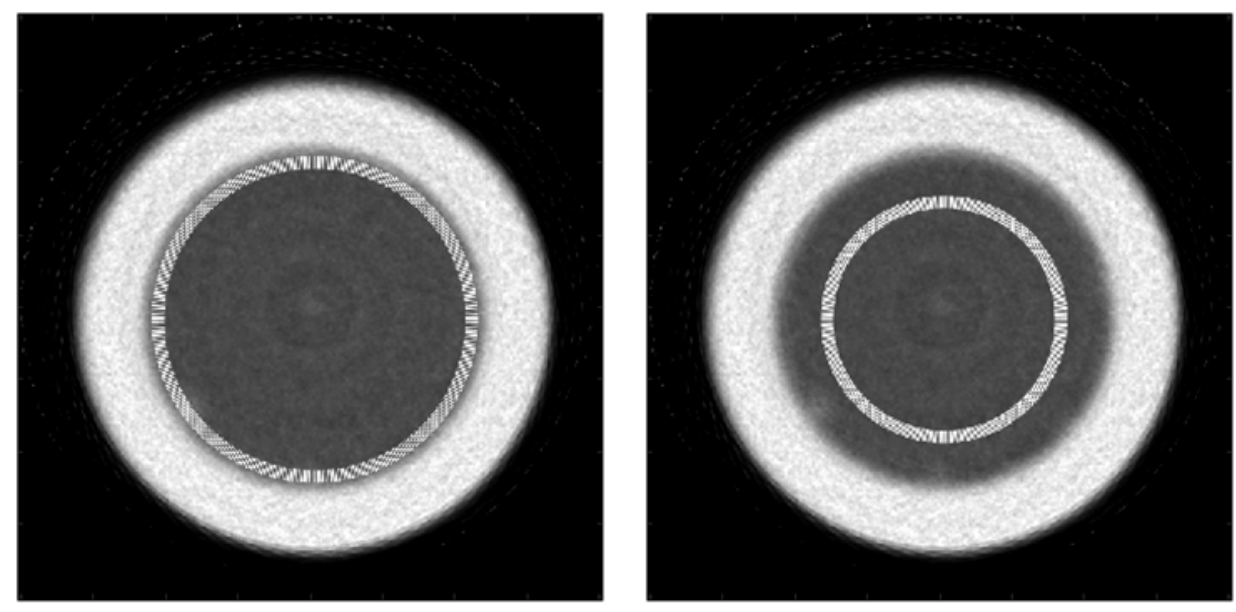

Figure 18. Locations of the attenuation length computation paths.

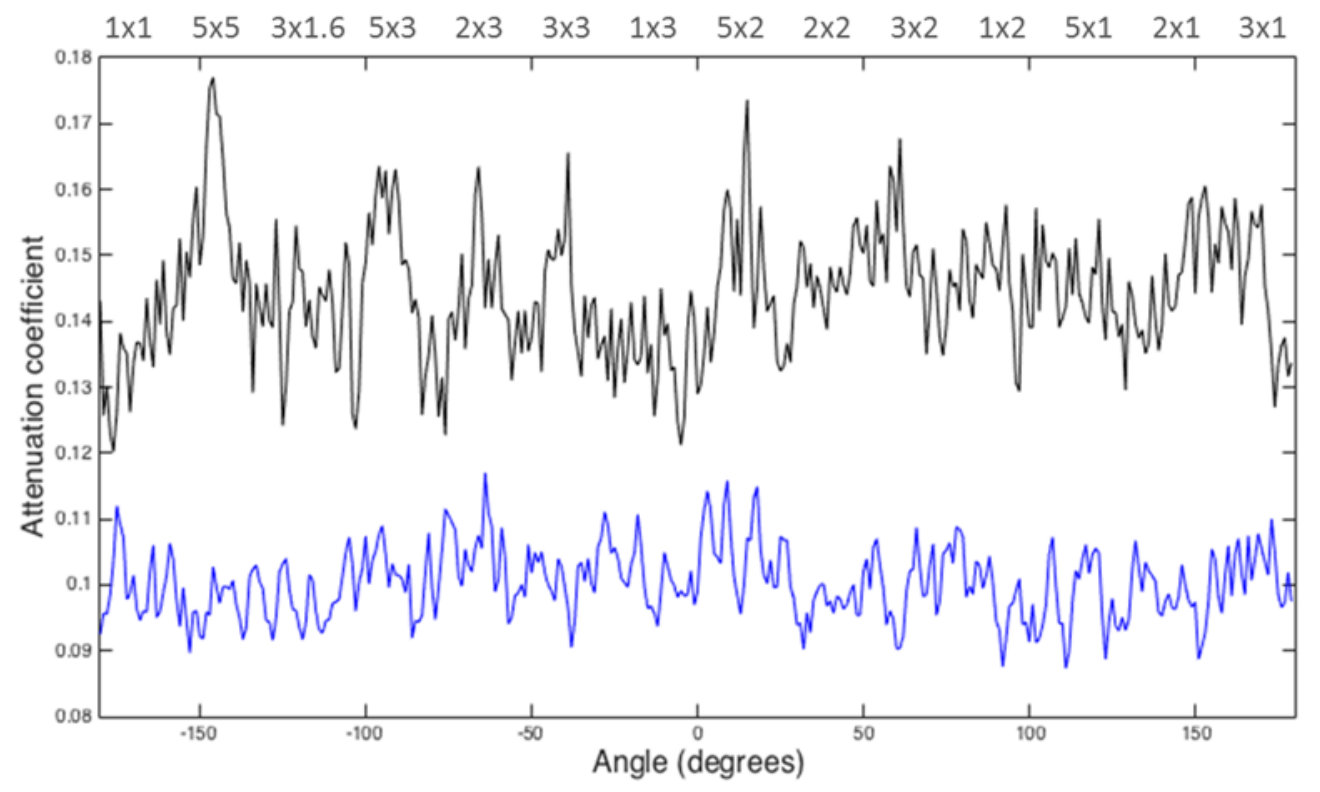

Figure 19. Measured neutron attenuation coefficient as a function of angle at a radius just inside the surface (upper) and deeper in the interior (lower).

\section{CONCLUSIONS}

These initial measurements have shown that features on the scale of a few millimeters can be measured with Oak Ridge National Laboratory's current fast neutron imaging system. The spatial resolution for both the axial pins and the surface inserts is about $3 \mathrm{~mm}$ with the current configuration of the equipment. Further data analysis may show improved performance and allow a more precise determination of the spatial resolution. Additional work is needed to provide a mathematical basis for that determination rather than simple visual inspection. Our current ING-27 DT generator has a neuron production spot size of about $3.5 \mathrm{~mm}$, which appears to be the limiting factor in the current system configuration. Our Monte Carlo simulation code currently does not fully account for this spot size. 


\section{PATH FOR CAPABILITY IMPROVEMENTS}

Generators with spot sizes as small as $1 \mathrm{~mm}$ are commercially available but have a reduced neutron production rate. Generators with spot sizes as small as $2 \mathrm{~mm}$ and with increased neutron output have been offered for commercial sale. This type of generator could in principle reduce the required measurement time as much as a factor of 60 over the present capability, but the achieved improvement will likely be somewhat less. With a better generator, and for larger samples for which a lower magnification factor is necessary, the current 1-inch detectors will become a limiting factor. ORNL has deployed two systems (Advanced Portable Neutron Imaging System - APNIS) with arrays of 3,200 neutron detection elements comprised of $10 \times 10$ element block detectors with individual detector pixels of $10 \mathrm{~mm}$. These systems allow a 2D image with a single exposure but were unavailable for use in the measurements described here. Detectability of a feature depends on additional factors beyond just the spatial resolution of the system. Our current Monte Carlo simulation code does not fully account for the effect of the DT generator spot size on spatial resolution and needs to be modified for future measurement planning.

\section{REFERENCES}

[1] J. T. Mihalczo et al., "Fast Neutron Imaging with API DT Neutron Generators," in Proceedings of International Scientific and Technical Conference Portable Neutron Generators and Technologies on Their Basis, pp. 55-62, Moscow, Russia (2012). 